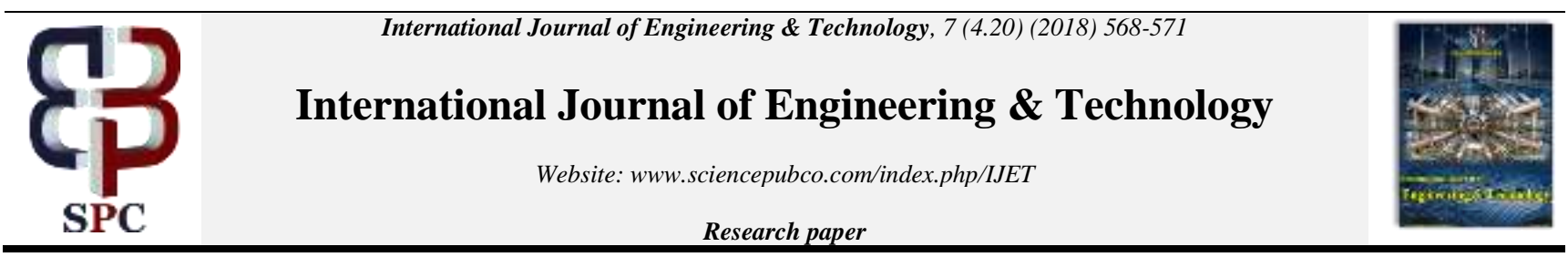

\title{
Improving the Properties of Clay Brick Using Polyvinyl Alcohol (PVA)
}

\author{
M. S. Abo Dhaheer ${ }^{1 *}$, Ammash, H. K. ${ }^{1}$, Albdiry, M. T. ${ }^{2}$ \\ $1 *$ Civil Department, College of Engineering, University of Al-Qadisiyah, Al-Diwaniyah, Iraq \\ ${ }^{2}$ Material Eng. Department, College of Engineering, University of Al-Qadisiyah, Al-Diwaniyah, Iraq \\ *Corresponding author Email:shamelm2000@gmail.com
}

\begin{abstract}
In this study, an experimental research was dedicated to investigate the properties of clay brick treated by polyvinyl alcohol (PVA). Two methods of treatment were conducted. The first contained treating clay brick by submerging the specimens in $1 \%, 2 \%$ and $3 \%$ of PVA solution, whereas the second involved coating the brick specimens with 6\% PVA (i.e. a high viscous solution). The treated specimens were allowed to dry under ambient temperature in the laboratory before being tested. Standard tests employed for brick specimens were applied. Regarding the specimens treated using the submerging method, results showed that there was a significant contribution of PVA to the compressive strength, total water absorption and efflorescence tests, in which the specimens reached the best performance when PVA was increased to $3 \%$. However, the brick specimens coated by PVA showed a slight increase in the compressive strength, but a noticeable decrease in the water absorption and efflorescence.
\end{abstract}

Keywords: absorption; Clay brick; compressive strength; efflorescence; polyvinyl alcohol.

\section{Introduction}

Clay brick is the oldest and most widely used construction material that has steadily gained popularity since its inception. It has been used in building material for decades as it has good structural properties and it does not require high maintenance, no fading, resistance to fungus and water, as well as it is relatively low cost [12]. Clay brick possesses a pleasing color and it has various surface textures that enable it to be architecturally more acceptable. Moreover, it is commonly used for the covering buildings and forms part of the brick surface wall system adopted for the cover-up of different types of buildings.

Different stacks of small elements with or without mortar or modification are compiled together to build a clay brick masonry. Shape and quality of elements (raw materials, clay particles), type of mortar or modification and fabrication process are all responsible on providing both the clay brick strength and resistance to withstand climate conditions (e.g., rainstorms, snow, high temperatures) and resistance to a human-induced deterioration [3]. From the other hand, using a crushed clay brick is suitable to produce a structural lightweight concrete with an adequate splitting tensile strength, compressive strength, thermal conductivity, workability and fire resistance, as it was revealed in [4-5]. Similarly, Munir et al. [6] proved that incorporating clay brick with various ratios of waste marble sludge resulted in an increased apparent porosity and water absorption of the material. It also resulted in generating of irregular shaped open pores in the structural material, which in turn resulted in improved thermal insulating properties.

Despite these superior properties of brick, there is a concern to be considered regarding its durability issue that is associated with its porosity and efflorescence. Therefore, the development of tech- niques, which could minimize these adverse influences of such inferior properties, is very important. In the construction industries, a judicious choice to tackle or minimize the adverse influence of the above shortcomings could be achieved by the exploitation of mineral admixtures [7-8] and/or polymers [9-10]. The former, although can assist in modifications of the material microstructure, it has to be added in relatively large amounts in order to be effective. The latter, however, can be added in small amounts in order to change the material microstructure, resulting in enchantment in the material properties [10].

In the field of construction industries, different types of the polymer have been used such as; re-dispersible polymer powders, liquid resins, monomers and water-soluble polymers [9]. Among these types, polyvinyl alcohol (PVA) has been utilized in numerous applications. It has been used to enhance the fresh and mechanical properties of cement-based products [11-13] and gypsum materials [14]. PVA also contributes in modification of pavement concrete as reported in [15]. This contribution could arise from the alteration in the material microstructure that results in decreasing of the pores volume by increasing the crystal overlapping interlocking and [1314].

Despite the aforementioned application of PVA, there was, by far, no study considered the role of using PVA polymeric resin as a modifier or surface pretreatment in clay bricks. Hence, this study aimed to investigate the role of (1) treating the clay brick specimens by submerging them in PVA solution and (2) modifying the specimens surface by a thin film coating, on the compressive strength, total water absorption and efflorescence properties. Based on the findings of the study, the optimal of PVA concentration was also determined. 


\section{Experimental program}

Locally produced clay bricks were used in this study. This satisfied Iraqi specification (IQS) No.25/1988 [16]. Polyvinyl alcohol (PVA) polymer, which is $98 \%$ hydrolysed, was used. The solution of polymer was prepared by dissolving 10, 20, 30, 60 of PVA powder (Figure 1) in 1 litre of water for 1, 2, 3, 6\% concentrations, respectively. After the powder was dissolved, the solution was allowed to cool down at ambient temperature in the laboratory. The experimental tests for the used clay bricks were carried out, including compressive strength, total water absorption and efflorescence, as shown in Figure 2.

In this study, two methods of treatment were conducted: the first included treating clay brick by submerging the specimens in $1 \%$, $2 \%$ and $3 \%$ of PVA solution for $24 \mathrm{hrs}$, and the second involved full coating (all specimen faces) the brick specimens with $6 \%$ PVA. All the treated specimens were left to dry in the laboratory environment until the testing age. For comparison, control specimens ( $0 \%$ PVA) were also tested. A total number of 75 specimens were used. For each of PVA percentage, 15 specimens (10 for compressive strength and water absorption tests, and 5 for efflorescence test) were tested according to IQS No.25/1988 [16]. The compressive strength test was performed on the specimens that had been used for the water absorption test (after immersing them for $24 \mathrm{hr}$ ).

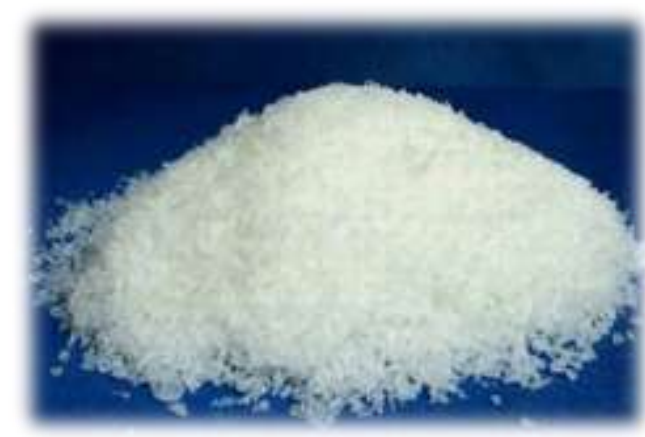

Fig. 1: Polyvinyl alcohol (PVA) powder

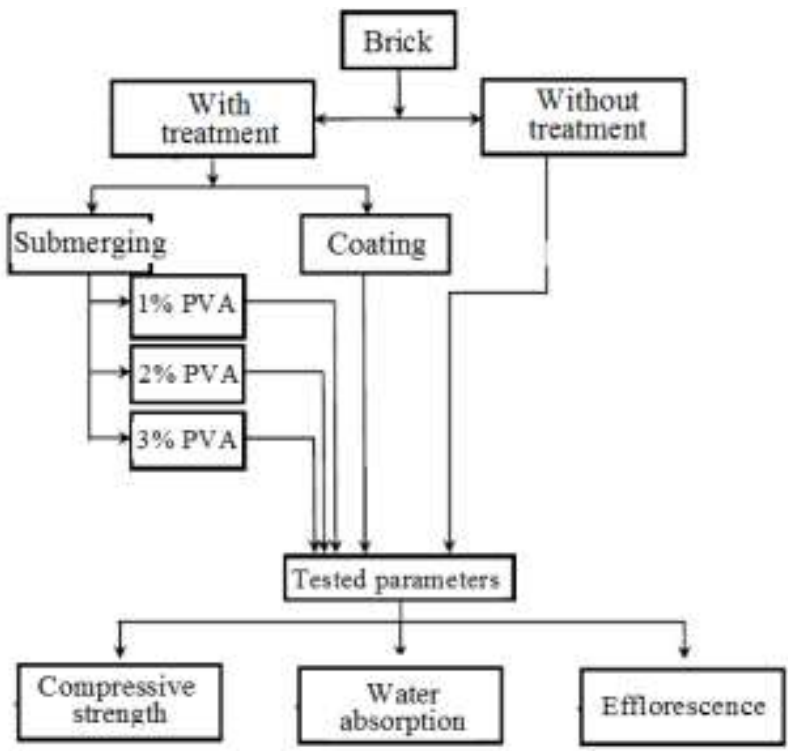

Fig. 2: Flow chart of the experimental program

Table 1: Results of compressive strength, total water absorption, and efflorescence tests.

\begin{tabular}{|c|c|c|c|c|c|}
\hline Treatment type & $\begin{array}{c}\text { Compressive strength } \\
(\mathrm{MPa})^{\mathrm{a}}\end{array}$ & $\begin{array}{c}\text { Water absorption } \\
(\%)^{\mathrm{a}}\end{array}$ & $\begin{array}{l}\text { Compressive strength } \\
\text {.relative to the control }\end{array}$ & $\begin{array}{l}\text { Water absorption } \\
\text { relative to the control }\end{array}$ & Efflorescence $^{b}$ \\
\hline $\begin{array}{l}\text { Control (without } \\
\text { treatment) }\end{array}$ & 9.35 & 23.36 & 0.0 & 0.0 & Dense \\
\hline $\begin{array}{l}\text { Immersing in } \\
1 \% \text { PVA }\end{array}$ & 10.03 & 22.14 & 1.07 & 0.95 & Average \\
\hline $\begin{array}{l}\text { Immersing in } \\
2 \% \text { PVA }\end{array}$ & 10.6 & 19.72 & 1.13 & 0.84 & Light \\
\hline $\begin{array}{l}\text { Immersing in } \\
3 \% \text { PVA }\end{array}$ & 11.37 & 17.74 & 1.22 & 0.76 & Light \\
\hline $\begin{array}{l}\text { Coating by } \\
6 \% \text { PVA }\end{array}$ & 9.94 & 19.25 & 1.06 & 0.82 & Light \\
\hline
\end{tabular}

${ }^{\text {a }}$ Values represent the average of ten brick specimens

${ }^{\mathrm{b}}$ Values represent the average of five brick specimens

\section{Results and discussion}

\subsection{Compressive strength}

In this study, the role of immersion clay brick in various percentages $(0 \%, 1 \%, 2 \%, 3 \%)$ of polyvinyl alcohol (PVA) solution on the compressive strength, total water absorption and efflorescence was evaluated. The effect of coating the clay brick by $6 \%$ PVA, on these properties, was also evaluated. Figure 3 shows the results of ten average values of the compressive strength for the control clay brick and the treated brick by PVA solution. It can be seen that the immersion of the brick specimens by PVA polymeric solution obviously improved the compressive strength where the $3 \mathrm{wt}$. \% PVA solution diluted in water indicated the highest value with about $22 \%$ improvement (Table 1). Whereas, coating the specimens by $6 \%$ PVA resulted in a decreased compressive strength of $9.94 \mathrm{MPa}$ compared to other PVA treatment. Nevertheless, it is still higher than the unmodified clay brick by about $6 \%$.

The reason behind that increase in compressive strength is that, after immersion, the PVA resin fills the pores inside the structure and replace the air gaps, resulting in lower internal stresses and increased compression resistance [12, 14]. In terms of the coating with $6 \%$ PVA, the higher value of PVA means the higher viscosity of the material that is difficult to penetrate into the internal pores of the structure, and consequently higher air gaps and lower compressive strength. 


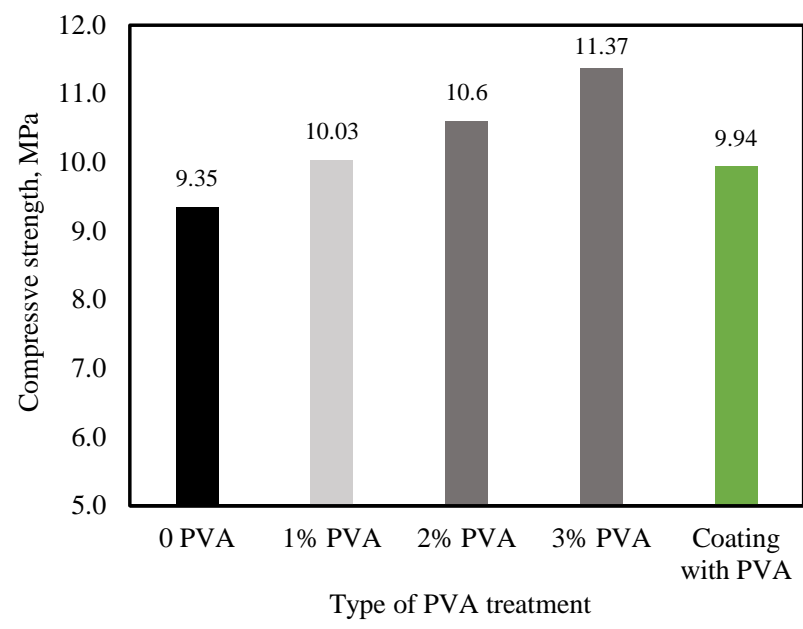

Fig. 3: Compressive strength of the tested specimens

\subsection{Total water absorption}

The water absorption is one of the important key factors affecting the brick durability, i.e., any reduction in brick water absorption results in an improvement in its durability performance. Figure 4 indicates the total water absorption of the treated clay brick and untreated with different PVA solution percentages. Increasing PVA up to $3 \%$ can effectively decrease the total water absorption by about $24 \%$. Also, it is clearly observed from Table 1 that the surface treatment of the brick specimens by PVA resulted in a reduced water absorption by about $18 \%$ compared with control specimens. As it was discussed earlier, the decrease in the porosity could be due to the pore-blocking effect of PVA polymer, in which the large proportion of pores volume is filled with PVA resin [13-14]. Accordingly, better compressive strength, better durability performance and lower water absorption percentage can be gained. Again, $3 \%$ PVA showed the typical percentage of the surface treatment.

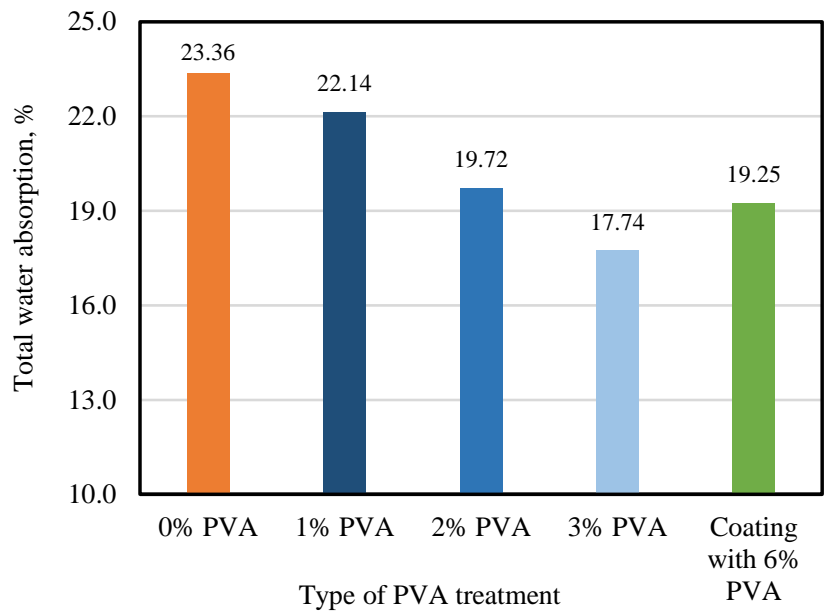

Fig. 4: Water absorption of the tested specimens

\subsection{Efflorescence}

Efflorescence can be defined as a white fine layer of water soluble salts left on the brick surface due to water movement via the existing pores. [17]. It occurs due to three main reasons, which are (1) the presence of water soluble salts, (2) rendering the salts into a soluble solution by an adequate amount of water, and (3) the existence of a path to salts solution to transfer to the brick surface [17]. The amount of efflorescence depends on porosity and pore size distribution of bricks. Typically, an increase in the brick efflorescence can be inferior to its durability performance. Therefore, there should be a technique that alleviating the influences of such inferior property and ensuring the brick durability. This has not been seriously investigated through the previous research work. Therefore, PVA application has been extended, in this study, to improve the durability of bricks as far as the efflorescence and water absorption are concerned. Table 1 shows the average values of five samples for efflorescence test. It can be revealed that the efflorescence was dense for the control brick specimens (no PVA treatment). Irrespective of the treatment methods (i.e. submerging or coating), efflorescence becomes lighter, thereby, contributing positively to the durability performance.

\section{Conclusion}

1. PVA can be advantageous in improving the compressive strength of bricks specimens, although the improvement was more observed in the specimens that were submerged in PVA solution than that coated with PVA.

2. The results confirmed the superiority of PVA in decreasing the total water absorption of the brick specimens in both treatment types.

3. There is a significant decreasing in the efflorescence of the specimens with increasing the dosage of PVA, irrespective of the treatment type. The decrease was less pronounced in the specimens that were soaked in $1 \%$ of the PVA solution.

4. It is interesting to mention that while PVA coating marginally increased the compressive strength of brick specimens, its influencing demonstrated a remarkable improvement in term of porosity and efflorescence.

5. The results of the present study were, indeed, encouraging and evidently proved that the use of PVA is a simple and reliable way to enhance the bricks performance.

\section{References}

[1] Aiyewalehinmi E O, Aderinola OS. Strength Properties Of Commercially Produced Clay Bricks In Six Different Locations/ States In Nigeria. International organization of Scientific Research. 2015: $5(8): 1-10$.

[2] Jayasinghe C. Comparative Performance of Burnt Clay Bricks and Compressed Stabilized Earth Bricks and Blocks. Engineer. 2007: 02:33-40.

[3] Koroth SR. Evaluation and Improvement of Frost Durability of Clay Bricks. PhD thesis. 1997. Concordia University. Montreal, Quebec, Canada.

[4] Wongsa A, Sata V, Nuaklong P, Chindaprasirt P. Use of crushed clay brick and pumice aggregates in lightweight geopolymer concrete. Construction and Building Materials. 2018;188:1025-34.

[5] Aliabdo AA, Abd-Elmoaty A-EM, Hassan HH. Utilization of crushed clay brick in cellular concrete production. Alexandria Engineering Journal. 2014;53(1):119-30.

[6] Munir MJ, Kazmi SMS, Wu Y-F, Hanif A, Khan MUA. Thermally efficient fired clay bricks incorporating waste marble sludge: An industrial-scale study. Journal of Cleaner Production. 2018;174:112235.

[7] Domone, P.L. and Illston, J. Construction materials: Their nature and behaviour. New York, USA, 2010: Spon Press.

[8] Siddique, R., Khan, M. I. Supplementary Cementing Materials: Silica Fume. Engineering Materials, Ch:2. Springer-Verlag Berlin Heidelberg, 2011: 67-119.

[9] Eren, F., Gödek, E., Keskinates, M., Felekog lu, KM, Felekog lu, B. Effects of latex modification on fresh state consistency, short term strength and long term transport properties of cement mortars, Constr. Build. Mater. 2016:133:226-233.

[10] Aggarwal, L.K., Thapliyal, P.C., Karade, S.R. Properties of polymer-modified mortars using epoxy and acrylic emulsions, Constr. Build. Mater. 2007:21 (2):379-383

[11] Brian NS, Ece E. Polyvinyl Alcohol Fiber-Reinforced Mortars for Masonry Applications. Materials Journal.107(1).

[12] Thong, C, Teo, D Ng, C. Application of polyvinyl alcohol (PVA) in cement-based composite materials: A review of its engineering properties and microstructure behavior. Constr. Build. Mater. 2016:107: 172-180. 
[13] Abo Dhaheer MS. Experimental investigation on the fresh and hardened properties of concrete incorporating polyvinyl alcohol. Al-Qadisiyah Journal for Engineering Science. 2018: 11(1): 134-147

[14] Abo Dhaheer MS, Haider K. Ammash, Kassim Kadhim Hameed Improvement of ordinary and pure gypsum properties by using polyvinyl alcohol (PVA). International Journal of Civil Engineering and Technology. 2018: 9(9): 323-334.

[15] Yaowarat; T, Suksun Horpibulsuk, Arul Arulrajah, Mehdi Mirzababaei. Compressive and Flexural Strength of Polyvinyl AlcoholModified Pavement Concrete Using Recycled Concrete Aggregates. Journal of Materials in Civil Engineering. 2018;30(4).

[16] Iraqi specification (IQS) No.25. Clay brick. Central Organization for Standardization and Quality Control:1988

[17] Efflorescence: Cause and Control. Masonry institutes of America. Based on a technical paper written by Michael Merrigan, P.E., originally published in The Masonry Society Journal, January-June, 1986. Available online, www.masonryinstitute.org. 